\title{
Phenolic compounds characterization by LC-DAD- ESI/MSn and bioactive properties of Thymus algeriensis Boiss. \& Reut. and Ephedra alata Decne
}

\author{
Borhane E.C. Ziani ${ }^{\mathrm{a}, \mathrm{b}, \mathrm{c}}$, Sandrina A. Heleno ${ }^{\mathrm{a}}$, Khaldoun Bachari ${ }^{\mathrm{b}}$, Maria Inês Dias ${ }^{\mathrm{a}}$, \\ Maria José Alves ${ }^{\mathrm{a}}$, Lillian Barros ${ }^{\mathrm{a}, *}$, Isabel C.F.R. Ferreira ${ }^{\mathrm{a}, *}$ \\ ${ }^{a}$ Centro de Investigacão de Montanha (CIMO), Instituto Politécnico de Bragança, Campus de Santa Apolónia, 5300-253 Bragança, Portugal \\ ${ }^{\mathrm{b}}$ Centre de Recherche Scientifique et Technique en Analyses Physico-Chimiques, CRAPC-Bouismail, Tipaza, Algeria \\ ${ }^{\mathrm{c}}$ Département de Technologie Alimentaire et Nutrition Humaine, Ecole nationale Supérieure Agronomique ENSA, Alger, Algeria
}

\section{A R T I C L E I N F O}

\section{Keywords:}

Phenolic profile/bioactivities

Thymus algeriensis

Ephedra alata

Infusion/decoction/hydroethanolic extract

\begin{abstract}
A B S T R A C T
Scientific research has been focused on finding natural occurring molecules from plant origin. Herein, infusion, decoction and hydroethanolic extracts of Thymus algeriensis Boiss. \& Reut. and Ephedra alata Decne. from Algeria were phytochemically characterized by LC-DAD-ESI-MSn, and evaluated regarding bioactive properties (antioxidant and antibacterial). Flavonol and flavone glycoside derivatives and phenolic acids, specially rosmarinic acid and kaempferol-O-glucuronide were the major compounds in T. algeriensis extracts. Otherwise, E. alata presented isoflavones and flavonol derivatives as main compounds, being hydroxypuerarin isomer 1 the major molecule. Aqueous extracts had significantly higher antioxidant activity, being this activity correlated with the amount of phenolic compounds. Antimicrobial activity of the extracts was tested against multi-resistant bacteria strains from clinical isolates. The obtained MIC values indicate that the hydroethanolic extracts revealed the highest effect, especially the one of T. algeriensis against Gram-positive bacteria. Hence, these plant extracts could be used in the development of bioactive ingredients.
\end{abstract}

\section{Introduction}

Natural products from plant origin, either as pure compounds or as standardized extracts, provide unlimited opportunities for new drug discoveries because of the unmatched availability of chemical diversity (Shahidi \& Ambigaipalan, 2015). These phytochemicals alone or in combination act as therapeutic agents in various disease complications (Ozcan, Akpinar-Bayizit, Yilmaz-Ersan, \& Delikanli, 2014). Some of their potential different biological activities and properties have been well described, being mainly related with antioxidant (Carocho \& Ferreira, 2013; Shahidi \& Ambigaipalan, 2015), antimicrobial (Ozcan et al., 2014; Parsaeimehr, Sargsyan, \& Javidnia, 2010) and antitumoral (Guimarães et al., 2014) properties.

Phenolic compounds are one of the most important classes of phytochemicals responsible for the possible protective role against oxidative damage diseases (coronary heart disease, stroke and cancers) (Carocho \& Ferreira, 2013; Guimarães et al., 2014; Shahidi \& Ambigaipalan, 2015). These molecules act against free radicals by antioxidant, redox and metal chelation capacity, acting as reducing agents, hydrogen donators or singlet oxygen quenchers (Carocho \& Ferreira, 2013). However, the increase in some infectious diseases caused by bacteria and the prevalent resistance to antibiotics, urges the scientists to search for new medicinal compounds from natural origin, which are novel and more efficient (Wink, 2015). Consequently, it is essential to identify and measure all the bioactive constituents of medicinal plants in order to ensure the biological research reliability and repeatability as well as to ensure the quality control over the pharmacological benefits and/or hazardous. Numerous analytical procedures (TLC, LC-DAD, LC-FLD, LC-MS, GC and CE) have been used in herbal products detection and identification (Wu et al., 2013; Ziani et al., 2018). LC-MS plays a prominent role as an analytical tool for detecting and identifying pharmacologically active metabolites and/or reactive metabolites, due to its high selectivity, reproducibility and simplicity (Wu et al., 2013).

Traditional Algerian medicinal plants have been described as sources of valuable bioactive compounds (Ziani et al., 2018). Besides its desertic and semi-desertic areas, Algeria contains a large pool of plants with high bioactive potential that can be used for medicinal applications, and for which many of them have not been explored, wheras numerous ethnobotanical approaches indicate that the local Saharan flora has been traditionally used in many cultures as a source of medicinal agents. Many studies have focused on these plants with

\footnotetext{
* Corresponding authors.

E-mail addresses: lillian@ipb.pt (L. Barros), iferreira@ipb.pt (I.C.F.R. Ferreira).
} 
pharmacologically active compounds with a potential therapeutic interest (Benarba, 2016; Ziani et al., 2018). Thymus algeriensis Boiss. \& Reut., belongs to the Lamiaceae family and is the most widespread North African species, endemic to Algeria and Tunisia. Fresh or dried, it is largely used only as a culinary herb, being its chemical composition already studied (Giweli, Džamić, Soković, Ristić, \& Marin, 2013; Guesmi, Ben Farhat, Mejri, \& Landoulsi, 2014). Although the results of its biological activity are still scarce, $T$. algeriensis is used in traditional medicine, as a fresh or dry seasoning, in respiratory and digestive tube disorders and against abortion (Giweli et al., 2013), being also used in the treatment of infectious diseases (e.g. gastrointestinal, dysentery, colds, diarrhea, prostate adenoma).

Ephedra alata Decne. (Ephedraceae family), Arabic name: Alanda, is a perennial genus of non-flowering seed with light green densely branched dioecious small and perennial stiff shrub, about $50-100 \mathrm{~cm}$ tall (Al-rimawi et al., 2017). The native land for this species is Iran, Algeria, Iraq, Chad, Egypt, Palestine, Lebanon, Jordan, Saudi Arabia, Morocco, Syrian Arab Republic, Libya, Mauritania, Mali, Somalia and Tunisia, where it grows wildly on the gravely rocky, sandy and clay soil in arid environments often near shifting sand dunes (Jaradat, Hussen, \& Al Ali, 2015). The decoction of E. alata stem is used in the folk medicine as a potential stimulant, deobstruent, to treat different disorders (e.g. kidney, bronchi, circular system, digestive system disorders), to relief asthma attack and as antifungal (Al-Qarawi, Abd Allah, \& Abeer, 2012). It is also used in cancer treatment and the plant stems are chewed to treat bacterial and fungal infections (Jaradat et al., 2015). Previous studies have shown that the aqueous extracts from this plant present in vitro anticancer activities, which have induced apoptosis, inhibiting proliferation with invasive behavior, causing the induction of cell cycle arrest, and the suppression of tumorangiogenesis (Shukla \& Mehta, 2015). Furthermore, it has also shown antimicrobial effects (Ghanem \& El-magly, 2008; Parsaeimehr et al., 2010).

To the authors' best knowledge, there are no published reports describing the phenolic composition of $T$. algeriensis and E. alata. Therefore, the present study aims to investigate these two Algerian medicinal plants from the arid regions, by using three types of extracts (aqueous extracts obtained by infusion and decoction, and hydroethanolic extracts), in order to identify the main bioactive compounds and evaluate their antioxidant and antibacterial activity.

\section{Material and methods}

\subsection{Plant material and samples preparation}

The two medicinal plant species: Ephedra alata Decne ssp. alenda (Ephedraceae) Local name: l'Alenda, and Thymus algeriensis Boiss. \& Reut. (Lamiaceae) Local name: Mazoukcha, were respectively harvested from Biskra $\left(34^{\circ} 50^{\prime} 14.2^{\prime \prime} \mathrm{N} 5^{\circ} 37^{\prime} 49.4^{\prime \prime} \mathrm{E}\right)$ and Tebessa $\left(35^{\circ} 25^{\prime} 56.3^{\prime \prime} \mathrm{N}\right.$ $8^{\circ} 01^{\prime} 30.6^{\prime \prime} \mathrm{E}$ ) arid and semi-arid Eastern arias of Algeria, during September 2016. The selected sites and gathering practices took into account local consumer's criteria for the use of these species and the optimal growth stage and gathering period of each species. Only the aerial parts of these plants were used to prepare the extracts. The voucher specimens were deposited at the Department of Botanic of the National Superior School of Agronomy (ENSA), Algiers, where the morphological key characters from the Flora of Quezel and Santa (1963) were used for plant identification. The samples were shadedried in a dark, dry place and at room temperature for 30 days, stored into cardboard bags, and further transported to the School of Agriculture, Polytechnic Institute of Bragança, Portugal, where all the analyses were carried out. The dry plants were grinded in the laboratory scale mill (Grindomix, Retsch, Germany) to obtain homogenous samples and stored at room temperature for subsequent use.

\subsection{Extracts preparation}

Infusion and decoction were the chosen methods according with traditional healers in order to mimic as closely as possible the traditional 'herbal' drug administration. An hydroethanolic extraction was also prepared for extractability and bioactivity comparison.

The infusion was obtained by extracting $1 \mathrm{~g}$ of the plant material at a ratio of $1: 100 \mathrm{~m} / \mathrm{v}$, with distillated boiling water $\left(100^{\circ} \mathrm{C}\right)$, allowed to infuse for $5 \mathrm{~min}$ at room temperature, and then filtered through Whatman No. 4 paper. However, for decoctions preparation, $1 \mathrm{~g}$ of the plant material was accurately added to $100 \mathrm{~mL}$ distilled water and boiled together, afterwards, the mixture was left boiling for $5 \mathrm{~min}$ and then filtered through Whatman No. 4 paper.

The obtained infusions and decoctions were frozen and further lyophilized (FreeZone 4.5 model 7,750,031, Labconco, KS, USA).

For the hydroethanolic extraction, each sample $(1 \mathrm{~g})$ was extracted twice by maceration in ethanol/water $(30 \mathrm{~mL}, 80: 20, v / v)$ at $25^{\circ} \mathrm{C}$ with constant stirring rate $(150 \mathrm{rpm}$ for $1 \mathrm{~h})$ and subsequently filtered through a Whatman No. 4 paper. The combined hydroethanolic extracts were concentrated at $40^{\circ} \mathrm{C}$ by a rotary vacuum evaporator (Büchi R210, Flawil, Switzerland) and the remaining water residue was then lyophilized.

\subsection{Phenolic compounds analysis by LC-DAD-ESI/MSn}

The previous mentioned extracts were re-dissolved in water and in ethanol/water (80:20, v/v) for the aqueous and hydroethanolic extracts, respectively, and analyzed using a concentration of $5 \mathrm{mg} / \mathrm{mL}$. LC-DAD-ESI/MSn analysis was carried out using chromatographic system Dionex Ultimate 3000 UPLC with a diode array detector (DAD) and connected to a Linear Ion Trap LTQ XL mass spectrometer (Thermo Scientific, San Jose, CA, USA), following a procedure previously performed by Bessada, Barreira, Barros, Ferreira, and Oliveira (2016). This system consists of a diode array detector coupled to an electrospray ionization mass detector (LC-DAD-ESI/MSn). Waters Spherisorb S3 ODS- $2 \mathrm{C}_{18}$ column $(3 \mu \mathrm{m}, 4.6 \times 150 \mathrm{~mm}$, Waters, Milford, MA, USA) allowed chromatographic separation and the gradient used consisted of the following solvents (A) $0.1 \%$ formic acid (LAB-SCAN analytical sciences, Gliwice, Poland) in water, and (B) acetonitrile (LAB-SCAN analytical sciences, Gliwice, Poland). The gradient elution applied was: $15 \%$ B (0-5 min), 15\%-20\% B (5-10 min), 20-25\% B (10-20 min), $25-35 \%$ B (20-30 min), and $35-50 \%$ B (30-40 min); the column was then re-equilibrated using a flow rate of $0.5 \mathrm{~mL} / \mathrm{min}$. Data were collected simultaneously with a DAD $(280,330$ and $370 \mathrm{~nm})$ and in a mass spectrometer. Negative mode was chosen for MS detection on a Linear Ion Trap LTQ XL mass spectrometer (Thermo Finnigan, San Jose, CA, USA). Sheath gas (nitrogen) was kept on 50 psi. Other parameters settings: $325^{\circ} \mathrm{C}$ of source temperature, $5 \mathrm{kV}$ of spray voltage, $-20 \mathrm{~V}$ of capillary voltage, $-66 \mathrm{~V}$ of tube lens offset, and 35 arbitrary units of collision energy. The full scan captured the mass between $\mathrm{m} / \mathrm{z} 100$ and 1500. Xcalibur ${ }^{\circledast}$ data system (Thermo Finnigan, San Jose, CA, USA) was used for data acquisition.

Quantification of these compounds was calculated from calibration curves $(2.5-200 \mu \mathrm{g} / \mathrm{mL})$ of each available phenolic standard (apigenin 6- $C$-glucoside, apigenin-8- $C$-glucoside, apigenin 7-O-glucoside, naringenin, quercetin 3-O-glucoside, rosmarinic acid, kampherol-3-O-rutinoside; myrcetin; isorhamnetin-3-O-glucoside; and quercetin-3-Oglucoside; all with $\geq 99 \%$ HPLC purity; Extrasynthèse, Genay, France). constructed upon the UV signal, and the results are expressed in mg per $\mathrm{g}$ of extract.

\subsection{Bioactive properties of the prepared extracts}

\subsubsection{Antioxidant activity evaluation}

The antioxidant activity was evaluated by DPPH radical-scavenging, reducing power (RP), inhibition of $\beta$-carotene bleaching in the presence 
of linoleic acid radicals (CBI) and inhibition of lipid peroxidation in brain cell homogenates (TBARS). For all the extracts, serial dilutions $(0.039-5.00 \mathrm{mg} / \mathrm{mL})$ were prepared from the stock solution $(5 \mathrm{mg} / \mathrm{mL})$ and further submitted to four distinct in vitro assays previously described by the authors (Bessada et al., 2016). The extract concentrations providing $50 \%$ of antioxidant activity or 0.5 of absorbance $\left(\mathrm{EC}_{50}\right)$ were calculated from the graphs of antioxidant activity percentages (DPPH, $\beta$-carotene bleaching and TBARS assays) or absorbance at $690 \mathrm{~nm}$ (reducing power assay) against extract concentrations. Trolox was used as standard.

\subsubsection{Antibacterial activity evaluation}

2.4.2.1. Bacteria Stains. All the bacterial stains used were clinical isolates obtained from infected patients hospitalized in the Local Health Unit of Bragança and Hospital Centre of Trás-os-Montes and Alto-Douro-Vila Real, Northeast of Portugal. Six Gram-negative bacteria: Morganella morganii and Pseudomonas aeruginosa isolated from expectoration, Escherichia coli, E. coli extended producer of $\beta$ lactamases (ESBL), Klebsiella pneumoniae and $K$. pneumoniae, spectrum extended producer of $\beta$-lactamases (ESBL), isolated from urine; and four Gram-positive bacteria: Enterococcus faecalis isolated from urine, Listeria monocytogenes isolated from cerebrospinal fluid, Methicillinsensitive Staphylococcus aureus (MSSA) isolated from wound exudate, and methicillin-resistant $S$. aureus (MRSA) were tested.

MicroScan panels (MicroScan ${ }^{\circledR}$; SiemensMedical Solutions Diagnostics, West Sacramento, CA, USA) and microdilution plate method was used for the evaluation of the bacterial susceptibility to different antibiotics, using a methodology previously described by Dias et al. (2016). The determination of the MIC was performed according to the microdilution method, as described by Dias et al. (2016) using a rapid $p$-iodonitrotetrazolium chloride (INT) colorimetric assay. Different antibiotics were used as standards for Gram-negative bacteria, such as amikacin for K. pneumoniae ESBL and $P$. aeruginosa, amoxicillin/ clavulanic acid for $E$. coli and $K$. pneumoniae and gentamicin for $E$. coli ESBL.

\subsection{Statistical analysis}

Three repetitions of the samples were used and triplicates for each concentration were carried out in all the assays. Results are expressed as mean values and standard deviations (SD). The results were analyzed using one-way analysis of variance (ANOVA) followed by Tukey's HSD test with $p=.05$ (SPSS v. 23.0 program). Furthermore, a Pearson's correlation analysis between the antioxidant activity and all the analyzed compounds was carried out, with a $95 \%$ significance level.

\section{Results and discussion}

\subsection{Phenolic compounds profile}

The phenolic compounds characterization of Ephedra alata and Thymus algeriensis was performed by applying LC-DAD-ESI/MSn to three different extracts obtained from infusion, decoction and maceration in hydroethanolic mixtures. Data regarding retention time, $\lambda_{\max }$, pseudomolecular ion, main fragment ions in $\mathrm{MS}^{2}$, tentative identification, and quantification of the individual compounds are summarized in Tables 1 and 2.

The UV-Vis and mass spectra obtained by LC-DAD-ESI/MS analysis showed that the phenolic composition of T. algeriensis was characterized by the presence of seventeen compounds where six were phenolic acid derivatives (compounds $7^{\mathrm{TH}}, 11^{\mathrm{TH}}, 12^{\mathrm{TH}}, 15^{\mathrm{TH}}-17^{\mathrm{TH}}$ ) and eleven were flavonoids linked to glycosyl groups (compounds $1^{\mathrm{TH}}-6^{\mathrm{TH}}, 8^{\mathrm{TH}}-10^{\mathrm{TH}}$, $\left.13^{\mathrm{TH}}, 14^{\mathrm{TH}}\right)$. As phenolic acids, compound $12^{\mathrm{TH}}\left([\mathrm{M}-\mathrm{H}]^{-}\right.$at $\mathrm{m} / \mathrm{z} 359$, $\mathrm{RT}=22.27 \mathrm{~min}$ ) was positively identified according to the dissociation of the molecular ion which generated two fragment ions, that may correspond to the two main constituents of rosmarinic acid (Pacifico et al., 2016) and comparing with the characteristics of the commercial standard; it was the major phenolic compound present in the sample. Peak $7^{\mathrm{TH}}\left([\mathrm{M}-\mathrm{H}]^{-}\right.$at $\left.m / z 521, \mathrm{RT}=17.58 \mathrm{~min}\right)$ presented $162 \mathrm{u}$ (glycoside moiety) higher than compound $12 \mathrm{TH}$, therefore being tentatively identified as rosmarinic acid hexoside. Peak $11^{\mathrm{TH}}\left([\mathrm{M}-\mathrm{H}]^{-}\right.$at $\mathrm{m} / \mathrm{z} 555, \mathrm{RT}=21.57 \mathrm{~min}$ ) was identified as salvianolic acid $\mathrm{K}$, due to a similar fragmentation pattern described by (Hauck, Gallagher, Morris, Leemans, \& Winters, 2014). Compound $16^{\mathrm{TH}}\left([\mathrm{M}-\mathrm{H}]^{-}\right.$at $717 \mathrm{~m} / \mathrm{z}$, $\mathrm{RT}=29.97 \mathrm{~min}$ ) was tentatively identified as salvianolic acid B (also known as lithospermic acid B), due to the fragmentation pattern with successive losses of $198 \mathrm{u}$ (danshensu) or $180 \mathrm{u}$ (caffeic acid) units (Zeng, Xiao, Liu, \& Liang, 2006). Peaks $17^{\mathrm{TH}}$ and $15^{\mathrm{TH}}$, presented the same pseudomolecular ion ([M-H]- at $m / z 537$ ) releasing also the same fragment ions at $m / z 493$ and 359, and taking into account the finding mention by several authors (Heleno, Martins, João, Queiroz, \& Ferreira, 2015; Zeng et al., 2006); these compounds were tentatively assigned as lithospermic acid A isomer I and II.

The remaining compounds were identified as flavonoids, such as flavones (quercetin and kaempferol derivative), flavonols (apigenin and luteolin derivatives) and flavanones (eriodictyol and naringenin dervatives). Compounds $1^{\mathrm{TH}}, 4^{\mathrm{TH}}$ and $13^{\mathrm{TH}}$ were identified as apigenin derivatives, being compound $4^{\mathrm{TH}}$ positively identified by standard comparison with vitexin (apigenin-8-C-glucoside). Compound 1 ([M$\mathrm{H}]^{-}$at $m / z 593$ ) released the MS ${ }^{2}$ fragment ions at $m / z 473$ and 383 (loss of 120 and $90 \mathrm{mu}$ characteristic of $C$-hexosyl flavones), and at $m / z$ 353 corresponding to the apigenin aglycone (apigenin $+83 \mathrm{mu}$, bearing some sugar residues), which allowed the identification of this compound as apigenin- $C$-hexoside- $C$-hexoside (Ferreres, Silva, Andrade, Seabra, \& Ferreira, 2003). Thus, this compound was tentatively identified as apigenin-6,8-C-diglucoside. Compounds $8^{\mathrm{TH}}$ ([M$\mathrm{H}]^{-}$at $\left.m / z 461\right)$ and $13^{\mathrm{TH}}\left([\mathrm{M}-\mathrm{H}]^{-}\right.$at $m / z$ 445) released a unique fragment at $m / z 285$ and 269 , respectively corresponding to luteolin and apigenin, with the loss of a glucuronyl moiety $(-176 \mathrm{u}$ ), being tentatively assigned as luteolin-O-glucuronide and apigenin-O-glucuronide. These compounds were assigned to luteolin-7-O-glucuronide and apigenin-7-O-glucuronide, owing to the identification of this compound in other Thymus species (Miron, Plaza, Bahrim, Ibáñez, \& Herrero, 2011; Vergara-Salinas, Pérez-Jiménez, Torres, Agosin, \& Pérez-Correa, 2012). Similarly, peak $14^{\mathrm{TH}}\left([\mathrm{M}-\mathrm{H}]^{-}\right.$at $m / z 477$, and $\mathrm{MS}^{2}$ fragment ion at $m / z 285$ ) was tentatively assigned as kaempferol-O-glucuronide. Peaks $2^{\mathrm{TH}}$ and $3^{\mathrm{TH}}\left([\mathrm{M}-\mathrm{H}]^{-}\right.$at $\left.m / z 449\right)$ and $6^{\mathrm{TH}}\left([\mathrm{M}-\mathrm{H}]^{-}\right.$at $\left.m / z 433\right)$, consistent with eridictyol-O-hexoside (isomer 1 and 2 ) and naringenin$O$-hexoside, although the nature and position of the sugar residue could not be established. The samples presented three quercetin derivatives ( $\lambda_{\text {max }}$ around $354 \mathrm{~nm}$, and an MS ${ }^{2}$ fragment at $m / z 301$ ), being quercetin-3-O-glucuronide (compound $5^{\mathrm{TH}}$ ) and quercetin-3-O-glucoside (compound 9TH) positively identified by comparison with commercial standards. Peak $10^{\mathrm{TH}}\left([\mathrm{M}-\mathrm{H}]^{-}\right.$at $m / z$ 549) presented tree $\mathrm{MS}^{2}$ fragments, corresponding to the losses of a malonyl ( $-86 \mathrm{u})$ and hexosyl $(-162 \mathrm{u})$ moieties, thus being identified as quercetin- $O$-malonylglucoside.

Quercetin-3-O-glucoside was previously reported in Thymus vulgaris L. (thyme) (Vergara-Salinas et al., 2012), whereas luteolin-7-O-glucoside was identified in thyme infusions (Kulišić, Dragović-Uzelac, \& Miloš, 2006), leaves and wild thyme (T. serpyllum Boiss.) (Miron et al., 2011; Vergara-Salinas et al., 2012). The presence of eriodictyol in different Thymus species has been reported by Boros et al. (2010) and Miron et al. (2011). Nonetheless, to the author's best knowledge the individual phenolic composition of Thymus algeriensis has not been previously reported.

Rosmarinic acid was the most abundant phenolic acid, while kaempferol-O-glucuronide was the main flavonoid present. Infusion preparations revealed the highest concentration of phenolic compounds, followed by decoctions and then hydroethanolic extracts (Table 1).

The LC-DAD-ESI/MSn profile of E. alata was characterized by the 
presence of 10 phenolic compounds, all belonging to flavonoids class, namely five isoflavones and five flavones.

Peaks $1^{\mathrm{EA}}$ and $2^{\mathrm{EA}}\left([\mathrm{M}-\mathrm{H}]^{-}\right.$at $\left.m / z 479\right)$ and $6^{\mathrm{EA}}\left([\mathrm{M}-\mathrm{H}]^{-}\right.$at $m / \mathrm{z}$ 461) were identified as myricetin 6-C-glucoside isomer 1 and 2 and as $5,5^{\prime}$-dihydroxy-3'-methoxyisoflavone-7-O- $\beta$-glucoside, taking into account the findings mentioned by Roriz, Barros, Carvalho, SantosBuelga, and Ferreira (2014) in Pterospartum tridentatum L. flowers. Peak $3^{\mathrm{EA}}\left([\mathrm{M}-\mathrm{H}]^{-}\right.$at $\left.m / z 445\right)$ released a fragment at $m / z 283\left([\mathrm{M}-\mathrm{H}-162]^{-}\right.$, loss of a glycosyl moiety) and was assigned as sissotrin (i.e., biochanin A 7-O-glucoside). Peaks $4^{\mathrm{EA}}, 5^{\mathrm{EA}}$ and $7^{\mathrm{EA}}$ all with the same pseudomolecular ion $[\mathrm{M}-\mathrm{H}]^{-}$at $m / z 445$, were identified as hydroxypuerarin isomers (hydroxydaidzein-8-C-glucoside isomers 1,2 , and 3), taking into account the characteristics identified by Prasain et al. (2007). Quercetin-3-O-rutinoside (compound $8^{\mathrm{EA}}$ ) and isorhamnetin-3-O-glucoside (compound $9^{\mathrm{EA}}$ ) were positively identified by comparison with commercial standards. Compound $10^{\mathrm{EA}}\left([\mathrm{M}-\mathrm{H}]^{-}\right.$at $\left.\mathrm{m} / \mathrm{z} 461\right)$ released two fragments at $m / z 431$ (loss of a deoxyhexoyl moiety, $-146 \mathrm{u}$ ) and 285 (loss of another deoxyhexoyl moiety, $-146 \mathrm{u}$ ), corresponding to a kaempferol derivative, and was identified as kaempferol-O-di-deoxyhexoside.

To the authors' best knowledge, few previous works were conducted regarding the phenolic composition of $E$. alata. However, the presence of the myricetin derivatives, such as myricetin 3-rhamnoside have been also reported in the hydroethanolic extract of $E$. alata from Palestine (Al-rimawi et al., 2017). The isoflavones biochanin A and the diazein, as well as the quercitin were also previously detected in many ephedracontaining dietary supplements purchased from the market in arkansasUnited states (Grippo, Capps, Rougeau, \& Gurley, 2007).Whilst, kaempferol-3-O-rhamnoside and quercetin-3-O-rhamnoside were identified in E. alata growing in the Egyptian desert (Nawwar, El-sissi, \& Barakat, 1984).

The most abundant compound was hydroxypuerarin isomer 1 , and contrarily to $T$. algeriensis, the aqueous extract prepared by decoction revealed the highest amount of phenolic compounds (Table 2).

\subsection{Antioxidant activity}

The evaluation of the antioxidant activity of the extracts was performed by following four different in vitro protocols: 2,2-diphenyl-1picrylhydrazyl (DPPH), reducing power, $\beta$-carotene bleaching inhibition and lipid peroxidation inhibition in brain cell homogenates. The results are summarized in Table 3 . For both plants, all the preparations revealed antioxidant activity with different performances. The aqueous extracts (infusions and decoctions) showed very similar behavior with lower $\mathrm{EC}_{50}$ values, while the hydroethanolic extracts showed lower antioxidant activity (higher $\mathrm{EC}_{50}$ values). T. algeriensis infusion and decoction presented the lowest values $\left(\mathrm{EC}_{50} 26.3 \mu \mathrm{g} / \mathrm{mL}\right.$ and $22.2 \mu \mathrm{g} /$ $\mathrm{mL}$, respectively) for the TBARS formation inhibition assay, meanwhile for $E$. alata infusion and decoction, RP assay revealed the most promising results. With the exception of CBI, T. algeriensis aqueous extract obtained by decoction demonstrated the highest antioxidant activity, whilst the infusions of $E$. alata showed the highest antioxidant activity. The mechanisms involved in the assays used to evaluate the antioxidant activity are different and, therefore, each plant preparation can have different compounds with specific capacities to participate in those mechanisms related to scavenging radical species, suppressing ROS/ RNS formation by inhibiting some enzymes or chelating trace metals involved in free radical production, thereby forming stable products, which do not initiate or propagate radical reactions (Carocho \& Ferreira, 2013). Indeed, the solvent type had some influence on the antioxidant activity, as it was exemplified by the different activities measured in the hydroethanolic extracts, when compared to the remaining assayed extracts obtained through aqueous extraction.

Methanolic extract of the aerial parts of $T$. hirtus sp algeriensis Boiss. \& Reut. growing in Gafsa, Tamerza and Kairouan in Tunisia (Guesmi et al., 2014), was also reported to have high antioxidant properties (in
$\%)$ as free radical inhibitors and scavengers, exhibited by DPPH assay (93\%), protonated radical ABTS (75\%) and $\beta$-carotene bleaching inhibition (50\%). To the authors' best knowledge, no reports are available on the infusion, decoction or hydroethanolic extracts of T. algeriensis. However, E. alata from Palestine (Al-rimawi et al., 2017), extracted with water, $80 \%$ ethanol, and pure ethanol has been reported as antioxidant, and the authors described higher activity, with higher contents in polyphenols, using higher polarity solvents. Thus, the highest radical scavenging activity (RSA) was reported for the hydroethanolic extract $(78 \mu \mathrm{g} / \mathrm{mL}$ for DPPH and $57 \mu \mathrm{g} / \mathrm{mL}$ for ABTS); both aqueous and ethanol:water extracts presented high correlation factors between polyphenols and the antioxidant activity measured by ferric reducing antioxidant power (FRAP), cupric reducing antioxidant capacity (CUPRAC), DPPH and ABTS radical scavenging activity. Moreover, Jaradat et al. (2015) reported results for the methanolic extract of $E$. alata from Jenin, Palestine regarding RSA, also showing lower $\mathrm{EC}_{50}$ values $(16.03 \mu \mathrm{g} / \mathrm{mL}$ for DPPH). Both mentioned studies described higher antioxidant activity, regarding the RSA assay, in comparison to the ones displayed by the presently studied hydroethanolic extract $(540 \mu \mathrm{g} / \mathrm{mL})$. This discordance noted in relation to our sample from Algeria is probably due to the effect of the region and climatic conditions affecting the biosynthesis of phenolic compounds, and to the effect of the extraction solvent used. This can generate quantitative differences on the bioactive molecules and therefore influences the antioxidant activity. Parsaeimehr et al. (2010) studied Ephedra wild culture species from Iran (E. procera Fisch. \& Mey., E. pachyclada Boiss. and E. strobilacea Bunge), in which the methanolic extract of $E$. strobilacea in comparison to the other species revealed to have higher antioxidant activity evaluated on FRAP assay. The same trend was obtained with the hydroalcoholic mixture (ethanol, methanol and distilled water 7:3) of Ephedra intermedia Schrenk ex Meyer from Balochistan, Pakistan in DPPH free radical scavenging assay (Gul, Jan, Faridullah, Sherani, \& Jahan, 2017). To the author's best knowledge there are no reports regarding E. alata infusions and decoctions, which are known to be the most common forms of consumption of this species.

To establish the relationship between phenolic compounds and the antioxidant activity, linear correlation coefficients were calculated. Positive significant $(p<.05)$ correlations between the phenolic acids, such as rosmarinic acid, salvianolic acid $\mathrm{K}$ and $\mathrm{B}$, lithospermic acid $\mathrm{A}$ isomer I, and all the antioxidant assays were established, proving the significance effect of these compounds in the radical scavenging effect, reducing power and lipid peroxidation inhibition of the studied Thymus hirtus extracts. Similarly, flavonoid derivatives (flavones and flavonols glycosylated), such as apigenin-O-glucuronide, apigenin-6,8-dihexoside and apigenin-8-C-glucoside, as well as kaempferol-O-glucuronide, luteolin-7-O-glucuronid, quercetin- $O$-malonyhexoside, quercetin-O-glucuronide and quercetin-3-O-glucoside showed a positive significant $(\mathrm{p}<.05)$ correlation with all the antioxidant tests. Regarding total phenolic acids and total flavonoid contents, positive significant correlations $(\mathrm{p}<.05)$ were established between total phenolic content and the antioxidant assays. A study performed by Guesmi et al. (2014), on the methanolic extract of the same plant from Tunisia, demonstrate similar positive correlations between some phenolic compounds (vanillic acid, tyrosin, vanillin, (+)-catechin hydrate, rutin) and radical scavenging assays (DPPH and ABTS). Nevertheless, these authors verified no correlation with total flavonoids. Otherwise, previous studies with several Lamiaceae species such as Thymus vulgaris L. (Ramkissoon, Mahomoodally, Ahmed, \& Subratty, 2012), Salvia officinalis L., S. verbenaca L., S. aegyptiaca L. and S. argentea L. (Ben Farhat, Landoulsi, Chaouch-hamada, Sotomayor, \& Jordán, 2013) demonstrated close correlations between polyphenolics and antioxidant activity (Guesmi et al., 2014), which could support the effectiveness of these compounds as antioxidants. Otherwise, correlation analysis established for $E$. alata extracts among the different antioxidant parameters and polyphenols exhibited no correlations with all the antioxidant assays. 


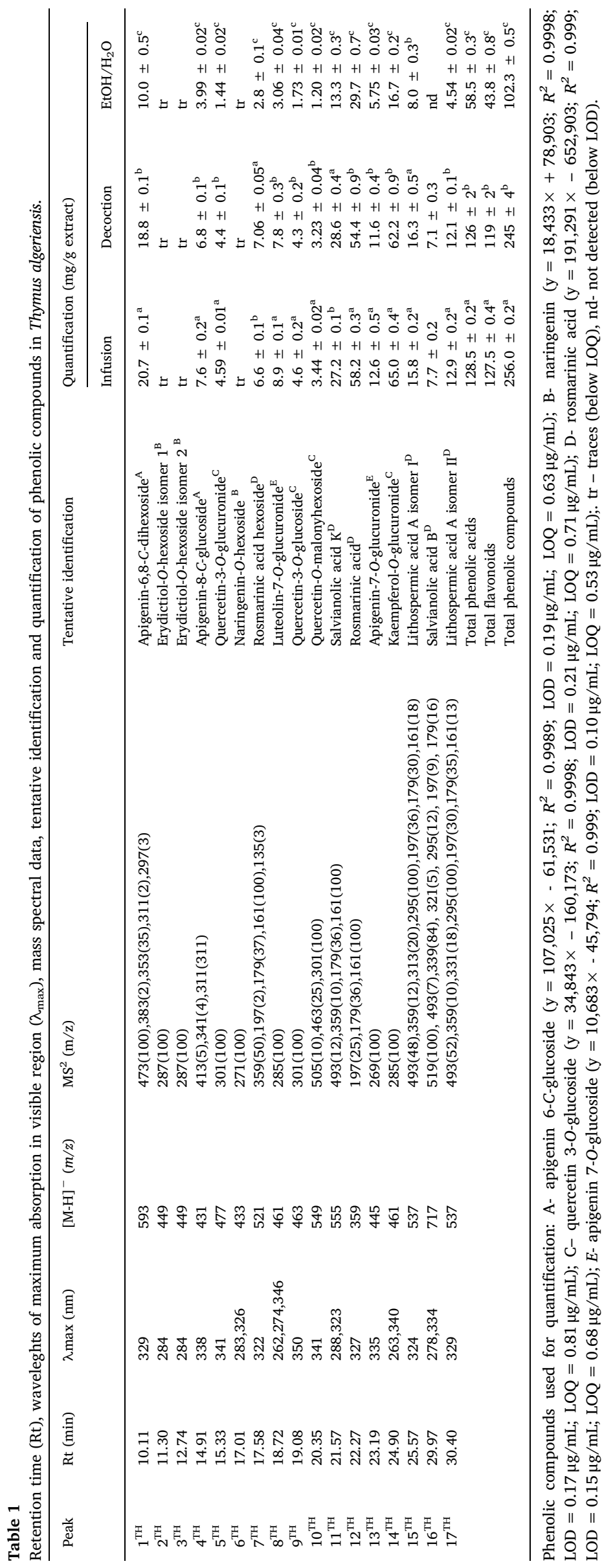


Table 2

Retention time (Rt), waveleghts of maximum absorption in visible region ( $\lambda$ max), mass spectral data, tentative identification and quantification of phenolic compounds in Ephedra alata.

\begin{tabular}{|c|c|c|c|c|c|c|c|c|}
\hline Peak & Rt (min) & $\lambda \max (\mathrm{nm})$ & $\begin{array}{l}{[\mathrm{M}-\mathrm{H}]^{-}} \\
(m / z)\end{array}$ & $\operatorname{MS}^{2}(m / z)$ & Tentative identification & \multicolumn{3}{|c|}{ Quantification (mg/g extract) } \\
\hline $1^{\mathrm{EA}}$ & 7.05 & 291,340 & 479 & $359(6), 341(36), 221(23), 167(28)$ & Myricetin- $C$-hexoside isomer $1^{\mathrm{A}}$ & $47.0 \pm 0.1^{\mathrm{b}}$ & $61 \pm 2^{\mathrm{a}}$ & $47.2 \pm 0.7^{b}$ \\
\hline 3 EA & 13.78 & 255,320 & 445 & $283(100)$ & Biochanin A 7-O-glucoside (sissotrin) ${ }^{\mathrm{B}}$ & $6.9 \pm 0.2^{\mathrm{b}}$ & $8.9 \pm 0.5^{\mathrm{a}}$ & $5.2 \pm 0.1^{\mathrm{c}}$ \\
\hline $4^{\mathrm{EA}}$ & 14.85 & 262,340 & 431 & $341(5), 311(100), 283(4), 239(3)$ & $\begin{array}{l}\text { Hydroxydaidzein-8- } C \text {-glucoside isomer } 1 \\
\text { (hydroxypuerarin isomer } 1)^{\mathrm{B}}\end{array}$ & $118.9 \pm 0.4^{b}$ & $159 \pm 5^{\mathrm{a}}$ & $89 \pm 4^{c}$ \\
\hline $5^{\mathrm{EA}}$ & 15.05 & 262,340 & 431 & $341(4), 311(100), 283(3), 239(2)$ & $\begin{array}{l}\text { Hydroxydaidzein-8- } C \text {-glucoside isomer } 2 \\
\text { (hydroxypuerarin isomer } 2)^{\mathrm{B}}\end{array}$ & $31.8 \pm 0.2^{\mathrm{b}}$ & $41.4 \pm 0.4^{\mathrm{a}}$ & $25.0 \pm 0.1^{\mathrm{c}}$ \\
\hline $7^{\mathrm{EA}}$ & 16.23 & 262,340 & 431 & $341(17), 311(100), 283(5), 239(4)$ & $\begin{array}{l}\text { Hydroxydaidzein-8-C-glucoside isomer } 3 \\
\text { (hydroxypuerarin isomer } 3)^{\mathrm{B}}\end{array}$ & $6.2 \pm 0.2^{\mathrm{b}}$ & $10.6 \pm 0.6^{\mathrm{a}}$ & $5.9 \pm 0.1^{b}$ \\
\hline $8^{\mathrm{EA}}$ & 17.89 & 351 & 609 & $301(100)$ & Quercetin-3-O-rutinoside $^{\mathrm{C}}$ & $3.41 \pm 0.02^{\mathrm{b}}$ & $4.266 \pm 0.003^{\mathrm{a}}$ & $2.76 \pm 0.02^{\mathrm{c}}$ \\
\hline $9^{\mathrm{EA}}$ & 18.25 & 368 & 477 & $357(100), 342(6), 314(4)$ & Isorhamnetin-3-O-glucoside ${ }^{\mathrm{C}}$ & $2.15 \pm 0.02^{\mathrm{c}}$ & $4.31 \pm 0.07^{\mathrm{a}}$ & $2.3 \pm 0.1^{\mathrm{b}}$ \\
\hline \multirow[t]{2}{*}{$10^{\mathrm{EA}}$} & 21.79 & 263,348 & 577 & $431(100), 285(12)$ & Kaempferol-O-di-deoxyhexoside ${ }^{\mathrm{C}}$ & $2.60 \pm 0.07^{\mathrm{b}}$ & $3.39 \pm 0.07^{\mathrm{a}}$ & $2.16 \pm 0.01^{\mathrm{c}}$ \\
\hline & & & & & Total flavonols & $83.4 \pm 0.2^{\mathrm{b}}$ & $103 \pm 2^{\mathrm{a}}$ & $73 \pm 1^{c}$ \\
\hline
\end{tabular}

Phenolic compounds used for quantification: A- myrcetin $\left(\mathrm{y}=23,287 \times-581,708 ; R^{2}=0.9988 ; \mathrm{LOD}=0.37 \mu \mathrm{g} / \mathrm{mL} ; \mathrm{LOQ}=0.98 \mu \mathrm{g} / \mathrm{mL}\right) ; \mathrm{B}-\mathrm{naringenin}$ $\left(\mathrm{y}=18,433 \times+78,903 ; \quad R^{2}=0.9998 ; \quad\right.$ LOD $=0.17 \mu \mathrm{g} / \mathrm{mL} ; \quad$ LOQ $\left.=0.81 \mu \mathrm{g} / \mathrm{mL}\right) ; \quad$ C- quercetin $\quad 3$-O-glucoside $\quad\left(\mathrm{y}=34,843 \times \quad-\quad 160,173 ; \quad R^{2}=0.9998 ;\right.$ $\mathrm{LOD}=0.21 \mu \mathrm{g} / \mathrm{mL} ; \mathrm{LOQ}=0.71 \mu \mathrm{g} / \mathrm{mL})$.

Table 3

Antioxidant activity of the different extracts from the studied plant species.

\begin{tabular}{|c|c|c|c|c|}
\hline \multirow[t]{2}{*}{ Plant extract } & \multicolumn{4}{|c|}{$\mathrm{EC}_{50}$ values $(\mu \mathrm{g} / \mathrm{mL})$} \\
\hline & $\begin{array}{l}\text { DPPH } \\
\text { scavenging } \\
\text { activity }\end{array}$ & Reducing power & $\begin{array}{l}\beta- \\
\text { Carotene } \\
\text { bleaching } \\
\text { inhibition }\end{array}$ & $\begin{array}{l}\text { TBARS } \\
\text { inhibition }\end{array}$ \\
\hline \multicolumn{5}{|l|}{ Thymus algeriensis } \\
\hline Infusion & $64.8 \pm 0.7^{\mathrm{b}}$ & $54.0 \pm 0.5^{\mathrm{b}}$ & $139 \pm 4^{\mathrm{b}}$ & $26.3 \pm 0.2^{\mathrm{b}}$ \\
\hline Decoction & $48 \pm 2^{\mathrm{c}}$ & $49.8 \pm 0.4^{\mathrm{c}}$ & $149 \pm 3^{\mathrm{a}}$ & $22.7 \pm 0.3^{\mathrm{c}}$ \\
\hline $\mathrm{EtOH} / \mathrm{H}_{2} \mathrm{O}$ & $131 \pm 3^{\mathrm{a}}$ & $100.2 \pm 0.5^{\mathrm{a}}$ & $85 \pm 3^{c}$ & $40.3 \pm 0.3^{\mathrm{a}}$ \\
\hline $\begin{array}{l}\text { Homoscedasticity* } \\
\quad(p \text {-value })\end{array}$ & 0.183 & 0.652 & 0.360 & 0.482 \\
\hline $\begin{array}{c}\text { 1-way ANOVA } \\
\text { (p-value) }\end{array}$ & $<0.001$ & $<0.001$ & $<0.001$ & $<0.001$ \\
\hline \multicolumn{5}{|l|}{ Ephedra alata } \\
\hline Infusion & $450 \pm 7^{b}$ & $108 \pm 1^{\mathrm{b}}$ & $131 \pm 1^{\mathrm{c}}$ & $128 \pm 2^{\mathrm{a}}$ \\
\hline Decoction & $455 \pm 6^{\mathrm{b}}$ & $109 \pm 3^{b}$ & $173 \pm 3^{\mathrm{b}}$ & $118 \pm 2^{\mathrm{b}}$ \\
\hline $\mathrm{EtOH} / \mathrm{H}_{2} \mathrm{O}$ & $540 \pm 3^{\mathrm{a}}$ & $377 \pm 4^{\mathrm{a}}$ & $502 \pm 8^{\mathrm{a}}$ & $118 \pm 4^{b}$ \\
\hline $\begin{array}{l}\text { Homoscedasticity* } \\
\text { (p-value })\end{array}$ & 0.028 & $<0.001$ & $<0.001$ & $<0.001$ \\
\hline $\begin{array}{c}\text { 1-way ANOVA** } \\
(p \text {-value })\end{array}$ & $<0.001$ & $<0.001$ & $<0.001$ & $<0.001$ \\
\hline
\end{tabular}

$\mathrm{EC}_{50}$ : Extract concentration corresponding to $50 \%$ of antioxidant activity or 0.5 of absorbance in reducing power assay. Trolox $\mathrm{EC}_{50}$ values: $41 \mu \mathrm{g} / \mathrm{mL}$ (reducing power), $42 \mu \mathrm{g} / \mathrm{mL}$ (DPPH scavenging activity), $18 \mu \mathrm{g} / \mathrm{mL}$ ( $\beta$-carotene bleaching inhibition) and $23 \mu \mathrm{g} / \mathrm{mL}$ (TBARS inhibition). ${ }^{1}$ The results are presented as the mean \pm SD.*Homoscedasticity among species was tested by the Levene test: homoscedasticity, $p>.05$; heteroscedasticity, $p<.05$. ${ }^{* *} \mathrm{p}<.05$ indicates that the mean value of the evaluated parameter of at least one species differs from the others (in this case multiple comparison tests were performed). For each species condition, means within a column with different letters differ significantly $(p<.05)$.

\subsection{Antibacterial activity}

The emerging antimicrobial drug resistant (ADR) pathogens is a serious problem in clinical environment and the plant-derived phenolic compounds may act as antimicrobials with generally low toxic effects (Wink, 2015). Ten clinical isolates representing both Gram-positive and Gram-negative bacteria and with a high rate of resistance to drugs were tested. The results of the obtained MIC values of the infusions, decoctions and hydroalcoholic extracts prepared from both plants are summarized in Table 4. Results clearly demonstrated different degrees of bacteria growth inhibition. Gram-positive bacteria were more sensitive to the studied extracts presenting lower MICs ranging from 2.5 to $10 \mathrm{mg} / \mathrm{mL}$. The decoction and infusion of T. algeriensis showed almost similar antibacterial activity by presenting similar MIC values, while the hydroethanolic extract revealed strongest activity as well as the hydroethanolic extract of $E$. alata, which exhibited MIC values of $5 \mathrm{mg}$ / $\mathrm{mL}$ against MRSA and MSSA. Otherwise, the lowest effect was observed for Gram-negative bacteria, revealing MICs ranging from 5 to $\geq 20 \mathrm{mg}$ / $\mathrm{mL}$. Pseudomonas aeruginosa was the less susceptible/most resistant bacteria (MIC $\geq 20 \mathrm{mg} / \mathrm{mL}$ ). For both plant species, infusions and decoctions had a weak effect, except against $E$. coli strains, which was the most susceptible microorganism with a MIC value of $0.625 \mathrm{mg} / \mathrm{mL}$. Although, there are no reports on the antibacterial effects of $T$. algeriensis aqueous and organic extracts, according to a study developed by Guesmi et al. (2014), the MICs obtained for the essential oil of Thymus hirtus sp. algeriensis from Tunisia are slightly higher than chloramphenicol, ampicillin and streptomycin. Essential oil of T. algeriensis from Zentan (Libya) showed also significant antibacterial activity, especially against $S$. aureus, Listeria monocytogenes as Gram-positive bacteria and also against $P$. aeruginosa, $E$. coli and $S$. typhimurium as Gram-negative bacteria (Giweli et al., 2013). Regarding infusion and decoction of $E$. alata, no effects were observed for the tested bacteria stains. On the contrary, high antibacterial and antifungal effects of this plant was previously reported in extracts prepared with water, methanol and acetonitrile, the latter exhibiting the most potent effect against all the microorganisms supplied by the Regional Center for Mycology and Biotechnology (RCMB), Al-Azhar University, Cairo, Egypt (Ghanem \& El-magly, 2008). The higher antimicrobial of essential oils and acetonitrile extracts of T. algeriensis is related to less polar compounds in comparison to the ones present in water or water: ethanol extracts; furthermore, in the present work multiresistant clinical isolated were used, being much less susceptible than ATCC bacteria used in the reported study. The results described are satisfactory, since the bacteria resistance to antibiotics is turning into a global issue. In this perspective, the exploiting of matrices with antibacterial agents are of high interest for the application in the pharmaceutical industry.

The obtained results suggest that the extracts present phytochemicals with a broad-spectrum activity against both Gram-positive and 
Table 4

Antimicrobial activity (MIC values $\mathrm{mg} / \mathrm{mL}$ ) of the prepared extracts from the studied plant species.

\begin{tabular}{|c|c|c|c|c|c|c|}
\hline \multirow[t]{2}{*}{ Antimicrobial activity MIC values (mg/mL) } & \multicolumn{3}{|c|}{ Thymus algeriensis } & \multicolumn{3}{|c|}{ Ephedra alata } \\
\hline & Infusion & Decoction & $\mathrm{EtOH} / \mathrm{H}_{2} \mathrm{O}$ & Infusion & Decoction & $\mathrm{EtOH} / \mathrm{H}_{2} \mathrm{O}$ \\
\hline \multicolumn{7}{|l|}{ Gram-negative bacteria } \\
\hline Escherichia coli ESBL & 5 & 10 & 5 & 20 & 20 & 5 \\
\hline Escherichia coli & 5 & 10 & 5 & 20 & 20 & 5 \\
\hline Klebsiella pneumoniae ESBL & 10 & 10 & 5 & 20 & 20 & 10 \\
\hline Klebsiella pneumoniae & 10 & 10 & 5 & 20 & 20 & 10 \\
\hline Morganella morganii & 10 & 10 & 5 & 20 & $>20$ & 20 \\
\hline Pseudomonas aeruginosa & 20 & 20 & 20 & $>20$ & $>20$ & 20 \\
\hline \multicolumn{7}{|l|}{ Gram-positive bacteria } \\
\hline Enterococcus faecalis & 10 & 10 & 10 & 20 & 20 & 10 \\
\hline Listeria monocytogenes & 10 & 10 & 10 & 20 & 20 & 10 \\
\hline MRSA & 5 & 10 & 2,5 & 10 & 20 & 5 \\
\hline MSSA & 5 & 10 & 2,5 & 10 & 20 & 5 \\
\hline
\end{tabular}

MIC-minimal inhibitory concentration; MSSA - methicillin susceptible Staphylococcus aureus; MRSA- Methicillin resistant S. aureus.

Gram-negative bacteria. According to the chemical characterization presented above, flavonoids (flavones and flavonols) were the major phenolic class in T. algeriensis. These compounds may act as antibiotics due to their ability to complex with extracellular and soluble proteins and also with bacterial cell walls, often leading to their inactivation and loss of function (Cushnie \& Lamb, 2011; Wink, 2015). Many research works identified the structure of flavonoids that possess antibacterial activity. Examples of such flavonoids found in the studied plants are apigenin derivatives (Nayaka, Londonkar, Umesh, \& Tukappa, 2014), luteolin derivatives (Kozyra, Biernasiuk, \& Malm, 2017), various quercetin glycosides and kaempferol and its derivatives (Teffo, Aderogba, \& Eloff, 2010). Other flavones, flavone glycosides (Kozyra et al., 2017; Nayaka et al., 2014), isoflavones (Mukne, Viswanathan, \& Phadatare, 2011), flavanones, isoflavanones, isoflavans, and flavonols (Cushnie \& Lamb, 2011; Ziani et al., 2018), flavonol glycosides (Cushnie \& Lamb, 2011) with antibacterial activity have also been identified. The site(s) and number of hydroxyl groups on the phenol group are thought to be related to their relative toxicity to microorganisms, with evidence that increased hydroxylation results in increased toxicity (Cushnie \& Lamb, 2011). In addition, some authors have found that more highly oxidized phenols are responsible for bacterial inhibition (Wink, 2015). The mechanisms thought to be responsible for phenolic toxicity to microorganisms include enzyme inhibition by the oxidized compounds, possibly through reaction with sulfhydryl groups or through more nonspecific interactions with the proteins and inhibition of cytoplasmic membrane function, as well as the inhibition of energy metabolism of the bacteria (Wink, 2015).

Among the studied plants, T. algeriensis hydroethanolic extract presented the strongest activity against the tested bacterial strains, presenting the lowest MIC values, and being MSSA and MRSA the most susceptible bacteria to this extract. This activity may be due to the presence of less polar compounds present in the hydroethanolic extract, since this extract presented lowest content in phenolic compounds.

Overall, T. algeriensis and E. alata infusions, decoctions and hydroethanolic extracts revealed antioxidant activity and antibacterial effects against clinical isolates, correlated with the amount of phenolic compounds (mainly in aqueous extracts). To the authors' best knowledge, this is the first report on detailed phenolic composition obtained by LCDAD-ESI/MSn. Phenolic acids (e.g., rosmarinic acid, salvianolic acid K and lithospermic acid) and glycolysed flavonoids (e.g. kaempferol-Oglucuronide, apigenin-6,8-C-dihexoside and apigenin-7-O-glucuronide) were the main phenolic compounds in T. algeriensis extracts. Whilst, for $E$. alata extracts, flavonols (e.g. myricetin- $C$-hexoside) and isoflavones (e.g. hydroxypuerarin and 5,5'-dihydroxi-methoxy-isoflavone-O-glucoside) were in majority. The present manuscript highlights the importance of natural products in the discovery of new bioactive compounds that may be successfully used as herbal drugs after in-vivo validation studies.

\section{Acknowledgements}

The authors are grateful to the Foundation for Science and Technology (FCT, Portugal) and FEDER under Programme PT2020 for financial support to CIMO (UID/AGR/00690/2013), S. Heleno grant (SFRH/BPD/101413/2014) and L. Barros contract. The authors are also grateful to the Interreg España-Portugal for financial support through the project 0377_Iberphenol_6_E.

\section{References}

Al-Qarawi, A. A., Abd Allah, E. F., \& Abeer, H. (2012). Effect of Ephedra alata on nucleic acids and nitrogen metabolism of seedborne Aspergillus flavus. Pakistan Journal of Botany, 44(1), 425-428.

Al-Rimawi, F., Abu-Lafi, S., Abbadi, J., Alamarneh, A. A. A., Raneen, A. S., \& Odeh, I (2017). Analysis of phenolic and flavonoids of wild Ephedra alata plant extracts by LC/PDA and LC/MS and their antioxidant activity. African Journal of Traditional, Complementary, and Alternative Medicines, 14(2), 130-141.

Ben Farhat, M., Landoulsi, A., Chaouch-Hamada, R., Sotomayor, J. A., \& Jordán, M. J. (2013). Characterization and quantification of phenolic compounds and antioxidant properties of Salvia species growing in different habitats. Industrial Crops and Products, 49, 904-914.

Benarba, B. (2016). Medicinal plants used by traditional healers from South-West Algeria: An ethnobotanical study. J. Intercult. Ethnopharmacol. 5(4), 320-330.

Bessada, S. M. F., Barreira, J. C. M., Barros, L., Ferreira, I. C. F. R., \& Oliveira, M. B. P. P. (2016). Phenolic profile and antioxidant activity of Coleostephus myconis (L.) Rchb.F.: An underexploited and highly disseminated species. Industrial Crops and Products, 89, 45-51.

Boros, B., Jakabová, S., Dörnyei, A., Horváth, G., Pluhár, Z., Kilár, F., \& Felinger, A. (2010). Determination of polyphenolic compounds by liquid chromatography-mass spectrometry in Thymus species. Journal of Chromatography A, 1217, 7972-7980.

Carocho, M., \& Ferreira, I. C. F. R. (2013). A review on antioxidants, prooxidants and related controversy: Natural and synthetic compounds, screening and analysis methodologies and future perspectives. Food and Chemical Toxicology, 51, 15-25.

Cushnie, T. P. T., \& Lamb, A. J. (2011). Agents recent advances in understanding the antibacterial properties of flavonoids. International Journal of Antimicrobial Agents, 38, 99-107.

Dias, M. I., Barros, L., Morales, P., Cámara, M., Alves, M. J., Oliveira, M. B. P. P., .. Ferreira, I. C. F. R. (2016). Wild Fragaria vesca L. fruits: a rich source of bioactive phytochemicals. Food \& Function, 7(11), 4523-4532.

Ferreres, F., Silva, B. M., Andrade, P. B., Seabra, R. M., \& Ferreira, M. A. (2003). Approach to the study of C-Glycosyl Flavones by Ion Trap HPLC-PAD-ESI/MS/MS: application to seeds of quince (Cydonia oblonga). Phytochemical Analysis, 14, 352-359.

Ghanem, S., \& El-Magly, U. I. A. (2008). Antimicrobial activity and tentative identification of active compounds from the medicinal Ephedra alata male plant. Journal of Taibah University Medical Sciences, 3(1), 7-15.

Giweli, A. A., Džamić, A. M., Soković, M. D., Ristić, M. S., \& Marin, P. D. (2013). Chemical composition, antioxidant and antimicrobial activities of Thymus algeriensis essential oil of wild-growing in Libya. Central European Journal of Biology, 8, 501-511.

Grippo, A. A., Capps, K., Rougeau, B., \& Gurley, B. J. (2007). Analysis of flavonoid phytoestrogens in botanical and ephedra-containing dietary supplements. Annals of Pharmacotherapy, 41(9), 1375-1382.

Guesmi, F., Ben Farhat, M., Mejri, M., \& Landoulsi, A. (2014). In-vitro assessment of antioxidant and antimicrobial activities of methanol extracts and essential oil of Thymus hirtus sp. algeriensis. Lipids in Health and Disease, 13(1), 1-12. 
Guimarães, R., Barros, L., Calhelha, R. C., Carvalho, A. M., Queiroz, M. J. R. P., \& Ferreira, I. C. F. R. (2014). Bioactivity of different enriched phenolic extracts of wild fruits from Northeastern Portugal: A comparative study. Plant Foods for Human Nutrition, $69,37-42$.

Gul, R., Jan, S. U., Faridullah, S., Sherani, S., \& Jahan, N. (2017). Preliminary phytochemical screening, quantitative analysis of alkaloids, and antioxidant activity of crude plant extracts from Ephedra intermedia indigenous to Balochistan. The Scientific World Journal, 2017, 1-7.

Hauck, B., Gallagher, J. A., Morris, S. M., Leemans, D., \& Winters, A. L. (2014). Soluble phenolic compounds in fresh and ensiled Orchard grass (Dactylis glomerata L.), a common species in permanent pastures with potential as a biomass feedstock. Agricultural and Food Chemistry, 62, 468-475.

Heleno, S. A., Martins, A., João, M., Queiroz, R. P., \& Ferreira, I. C. F. R. (2015). Bioactivity of phenolic acids: Metabolites versus parent compounds: a review. Food Chemistry, 173, 501-513.

Jaradat, N., Hussen, F., \& Al Ali, A. (2015). Preliminary phytochemical screening, quantitative estimation of total flavonoids, total phenols and antioxidant activity of Ephedra alata. Journal of Materials Environmental Science, 6(6), 1771-1778.

Kozyra, M., Biernasiuk, A., \& Malm, A. (2017). Natural drugs analysis of phenolic acids and antibacterial activity of extracts obtained from the flowering herbs of Carduus acanthoides L. Acta Poloniae Pharmaceutica N Drug Research, 74(1), 161-172.

Kulišić, T., Dragović-Uzelac, V., \& Miloš, M. (2006). Antioxidant activity of aqueous tea infusions prepared from oregano, thyme and wild thyme. Food Technology and Biotechnology, 44(4), 485-492.

Miron, T. L., Plaza, M., Bahrim, G., Ibáñez, E., \& Herrero, M. (2011). Chemical composition of bioactive pressurized extracts of Romanian aromatic plants. Journal of Chromatography A, 1218(30), 4918-4927.

Mukne, A. P., Viswanathan, V., \& Phadatare, A. G. (2011). Structure pre-requisites for isoflavones as effective antibacterial agents. Pharmacognosy Reviews, 5(9), 13-19.

Nawwar, M. A. M., El-Sissi, H. I., \& Barakat, H. H. (1984). Flavonoid constituents of Ephedra alata. Phytochemistry, 23(12), 2937-2939.

Nayaka, H. B., Londonkar, R. L., Umesh, M. K., \& Tukappa, A. (2014). Antibacterial attributes of apigenin, isolated from Portulaca oleracea L. International Journal of Bacteriology, 2014, 1-8.

Ozcan, T., Akpinar-Bayizit, A., Yilmaz-Ersan, L., \& Delikanli, B. (2014). Phenolics in human health. International Journal of Chemical Engineering and Applications, 5(5), 393-396.

Pacifico, S., Piccolella, S., Papale, F., Nocera, P., Lettieri, A., \& Catauro, M. (2016). A polyphenol complex from Thymus vulgaris L. Plants cultivated in the Campania region (Italy): New perspectives against neuroblastoma. Journal of Functional Foods, 20, 253-266.

Parsaeimehr, A., Sargsyan, E., \& Javidnia, K. (2010). A comparative study of the antibacterial, antifungal and antioxidant activity and total content of phenolic compounds of cell cultures and wild plants of three endemic species of Ephedra. Molecules, 15, 1668-1678.

Prasain, J. K., Reppert, A., Jones, K., Moore, D. R., II, Barnes, S., \& Lila, M. A. (2007) Identification of isoflavone glycosides in Pueraria lobata cultures by tandem mass spectrometry. Phytochemical Analysis, 18(1), 50-59.

Quezel, P., \& Santa, S. (1963). Nouvelle flore de l'Algérie et des régions désertiques méridionales. Nouvelle flore de l'Algérie et des régions désertiques méridionales (Vol Tome II) (pp. 350-1170). Paris: CNRS.

Ramkissoon, J. S., Mahomoodally, M. F., Ahmed, N., \& Subratty, A. H. (2012). Relationship between total phenolic content, antioxidant potential, and antiglycation abilities of common culinary herbs and spices. Journal of Medicinal Food, 15(12), 1116-1123.

Roriz, C. L., Barros, L., Carvalho, A. M., Santos-Buelga, C., \& Ferreira, I. C. F. R. (2014). Pterospartum tridentatum, Gomphrena globosa and Cymbopogon citratus: A phytochemical study focused on antioxidant compounds. Food Research International, 62, 684-693.

Shahidi, F., \& Ambigaipalan, P. (2015). Phenolics and polyphenolics in foods, beverages and spices: Antioxidant activity and health effects: A review. Journal of Functional Foods, 1-78.

Shukla, S., \& Mehta, A. (2015). Anticancer potential of medicinal plants and their phytochemicals: A review. Brazilian Journal of Botany, 38, 1-12.

Teffo, L. S., Aderogba, M. A., \& Eloff, J. N. (2010). Antibacterial and antioxidant activities of four kaempferol methyl ethers isolated from Dodonaea viscosa Jacq. Var. angustifolia leaf extracts. South African Journal of Botany, 76(1), 25-29.

Vergara-Salinas, J. R., Pérez-Jiménez, J., Torres, J. L., Agosin, E., \& Pérez-Correa, J. R. (2012). Effects of temperature and time on polyphenolic content and antioxidant activity in the pressurized hot water extraction of deodorized thyme (Thymus vulgaris). Journal of Agricultural and Food Chemistry, 60(44), 10920-10929.

Wink, M. (2015). Modes of action of herbal medicines and plant secondary metabolites. Medicine, 251-286.

Wu, H., Guo, J., Chen, S., Liu, X., Zhou, Y., Zhang, X., \& Xu, X. (2013). Recent developments in qualitative and quantitative analysis of phytochemical constituents and their metabolites using liquid chromatography - Mass spectrometry. Journal of Pharmaceutical and Biomedical Analysis, 72(151), 267-291.

Zeng, G., Xiao, H., Liu, J., \& Liang, X. (2006). Identification of phenolic constituents in Radix Salvia miltiorrhizae by liquid chromatography/electrospray ionization mass spectrometry. Rapid Communications in Mass Spectrometry, 20, 499-506.

Ziani, B. E. C., Barros, L., Boumehira, A. Z., Bachari, K., Heleno, S. A., Alves, M. J., \& Ferreira, I. C. F. R. (2018). Profiling polyphenol composition by HPLC-DAD-ESI/MSn and the antibacterial activity of infusion preparations obtained from four medicinal plants. Food \& Function, 9, 149-159. 